УАK 349.2

ББК 67.405.1

DOI 10.22394/1682-2358-2018-6-78-86

A.G. Chernyshova, Head of the Educational and Scientific Labo. ratory for Sociological Research, postgraduate student of the Social Disciplines and Humanities Department, University of Technology, Korolev

\section{SPECIFICS OF SOCIAL RESPONSIBILITY OF THE ROCKET AND SPACE ENTERPRISES IN EMPLOYEES ASSESSMENTS}

The social responsibility of rocket and space enterprises to the employees is considered. The results of the authorial social research of trade union activity in the rocket and space enterprises, as well as the compliance with the main parts of the collective agreement and social package are presented. The author concludes that employees of rocket and space enterprises are generally satisfied with their work and the work of trade unions and estimate their enterprise as socially responsible.

Key words and word-combinations: social responsibility, rocket and space enterprises, trade union, collective agreement, social package.
А.Г. Черныпиова, заведующий учебнонаучной лабораторией сочиологических исследований, аспирант кафедрь гуманитарньхх и соииальньх дисииплин Технологического университеma, г. Koporeb

(email: chernyshova-anna@bk.ru)

\section{СПЕЦИФИКА \\ СОЦИААЬНОЙ}

ОТВЕТСТВЕННОСТИ

ПРЕАПРИЯТИЙ

РАКЕТНО-КОСМИЧЕСКОЙ

ПРОМЫШАЕННОСТИ

\section{В ОЦЕНКАХ СОТРУАНИКОВ}

Аннотация. Рассматривается социальная
ответственность предприятий РКП перед его
работниками. Приводятся результаты авторско-
го социологического исследования деятельнос-
ти профессиональных союзов на предприятиях
РКП, соблюдения основных элементов коллек-
тивного договора и социального пакета. Делается
вывод о том, что сотрудники предприятий РКП
в целом удовлетворены работой профсоюзных
организаций и оценивают свое предприятие как
социально ответственное.
Ключевые слова и словосочетания: соци-
альная ответственность, РКП, профессиональ-
ный союз, коллективный договор, социальный
пакет.
С социально ориентированной рыноч-
ной экономике Россию Аолжны привести
глубокие преобразования во всех сферах
жизни, что в большой степени зависит от 
качественной работы всех социальных институтов [1]. Концентрированное понятие соџиально ориентированной модели развития страны получимо выражение в термине «соџиальное государство». В Конституции РФ закреплен принцип: «Российская Федераџия - соџиальное государство, политика которого направлена на создание условий, обеспечивающих достойную жизнь и свободное развитие человека» [2] .

В связи с переходом России к рыночным отношениям происходят преобразования во всех отраслях и сферах общественной жизни, меняется также система управления как человеческими ресурсами, так и трудовыми отношениями. В настоящее время одной из приоритетных задач становится соџиальная ответственность всех соџиальных институтов страны. Это проявляется в целом ряде параметров: государство является соџиальным; предпринимательство и бизнес заинтересованы в социальных инвестициях, в развитии человеческого капитала; работники имеют возможность защищать свои интересы через профессиональные союзы.

Сегодня существует множество определений понятия «соџиальная ответственность». Учреждения, организаџии и правительства осуществцяли определенные действия в различных аспектах соџиальной ответственности еще в конце XIX столетия, а в некоторых случаях и раньше. В период перехода к рыночной экономике, в середине 1990-х годов, понятие «социальная ответственность» стало широко применяться российскими исследователями и преАпринимателями. В настоящее время формируется понимание того, что социальная ответственность применима ко всем организациям, преАприятиям, учреждениям, которые берут на себя обязательства за вклад в устойчивое развитие общества.

В заявлении Президента РФ В.В. Путина о новом векторе развития российской соџиальной ответственности, высказанном РИАМО «Новости» 5 апреля 2018 г., подчеркивается: «Понятно, что прибымь - это Амя бизнеса главный приоритет. Но это не должно достигаться мюбой ценой. Вы знаете, почему я говорю об этом сегодня. Почему так важна ответственность бизнеса переА Аюдьми и переА обществом. Нельзя быть временщиками» [3] .

Социально ответственным в реалиях нашего времени является не только государство, но и предприятия, корпорации, организации и бизнес-сообщества, интегрирующие Аанный принцип в свою деятельность.

В управлении соџиальной политикой на преАприятиях немаловажное значение имеет такое понятие, как корпоративная социальная ответственность (KCO) - конџепџия, в соответствии с которой организации должны учитывать интересы общества, возмагая на себя ответственность за вцияние их деятельности на различные заинтересованные стороны [4, с. 5]. Следовательно, это действия предприятия, осушествляемые на добровольной основе, которые выходят за рамки основной деятельности, а также направценные на улучшение качества жизни как своих работников и членов их семей, так и общества в цемом. В научном мире понятие корпоративной социальной ответственности - КСО, существует с 1950-х годов, хотя после появления книги Э. Карнеги «Евангелие богатства» в 1899 г. Аискуссии о 
социальной ответственности бизнеса начались на Западе еще в конџе XIX начале XX в. Именно в это время были заложены основы «концепџии социальной ответственности бизнеса». Соџиальная ответственность преАприятия - это неотъемлемая часть соџиальной политики, проводимой на преАприятии [5] .

В настоящее время наиболее уязвимой стороной в трудовых правоотношениях явмяются работники предприятий, организаций. Аیя защиты прав и интересов сотрудников создаются и действуют профессиональные союзы. Основы для создания профессиональных союзов закреплены в ст. 30 Конституции РФ, где гарантируется право на создание профессиональных союзов и свободу деятельности такого рода общественных объединений [2]. В гл. 58 Трудового кодекса РФ подробно представлен регламент Аля осуществления деятельности профессиональных союзов. Принят и действует Федеральный закон от 12 января 1996 г. № 10-Ф3 «О профессиональных союзах, их правах и гарантиях деятельности». В Федеральных законах от 19 мая 1995 г. № 82-Ф3 «Об общественных объединениях», от 12 января 1996 г. № 7-Ф3 «О некоммерческих организациях», а также Гражданском кодексе РФ отражены отдельные нормы дмя профсоюзных организаций.

Основной задачей профсоюзов явцяется контроль за соблюдением прав и интересов работников работодателем, поэтому их главной функцией явмяется правозащитная - обеспечение, защита и охрана прав и интересов работников, а также восстановмение в правах, возмещение ущерба и привлечение к ответственности миџ, причастных к реализаџии трудового законодательства [6].

С целью изучения мнения сотрудников предприятий РКП о Аеятельности профсоюзных организаций и соблюдения руководством преАприятий и профсоюзами обязательных требований трудового законодательства на базе учебно-научной маборатории соџиологических исследований Технологического университета г. Королева в 2016-2017 гг. проведено социологическое исследование, проходившее в форме анкетирования более 300 сотрудников АО «Корпорация “Тактическое ракетное вооружение” и ПАО «РКК “Энергия”».

В рамках исследования выявцялась информированность сотрудников о намичии профсоюзной организации на предприятиях РКП. Подавляющее большинство респондентов $(93,4 \%)$ знают о сушествовании профсоюзной организации на предприятиях, в возрастной группе до Авадџати мет четверть опрошенных не проинформированы о деятельности профсоюзов, что вызвано, скорее всего, их недавним трудоустройством.

Целью исследования ставилось также узнать мнение сотрудников об эффективности работы профсоюзов по основным направлениям деятельности. Самым эффективным направлением деятельности профсоюзов, по мнению респондентов, является создание условий Аля культурного и нравственного развития чиенов профсоюза РКП (22,9\%).

Примерно одинаково респонденты оџенияи эффективность работы в обмасти защиты прав и интересов работников $(12,1 \%)$ и в сфере улучшения 
условий труда и отдыха (14,9\%). Наименее эффективной, по мнению участников опроса, явмяется деятельность профсоюзов в области работы наА усимением мотивации профсоюзного чценства $(5,0 \%)$ и привлечения сотрудников к управлению предприятием (4,3\%) (табл. 1$)$.

Таблица 1

Распределение ответов на вопрос:

«Оџените, пожалуйста, эФфективность работы профсоюзной организаџии по слеАующим основным направлениям",

$\%$ от общего числа опрошенных

\begin{tabular}{|c|c|c|c|c|c|}
\hline Направления работы & Высокая & Средняя & Низкая & $\begin{array}{l}\text { Крайне } \\
\text { низкая }\end{array}$ & $\begin{array}{l}\text { Затрудняюсь } \\
\text { ответить }\end{array}$ \\
\hline $\begin{array}{l}\text { Создание условий для культурного } \\
\text { и нравственного развития членов } \\
\text { профсоюза }\end{array}$ & 22,9 & 40,0 & 12,1 & 5,0 & 20,0 \\
\hline Улучшение условий труда и отдыха & 14,9 & 42,6 & 22,7 & 2,8 & 17 \\
\hline Защита прав и интересов работников & 12,1 & 34,3 & 21,4 & 9,3 & 22,9 \\
\hline $\begin{array}{l}\text { Содействие в создании условий } \\
\text { для профессионального роста }\end{array}$ & 8,5 & 18,4 & 31,9 & 14,9 & 26,2 \\
\hline $\begin{array}{l}\text { Обеспечение социальной защиты } \\
\text { каждому работнику в прямой } \\
\text { зависимости от его персонального } \\
\text { трудового вклада }\end{array}$ & 7,9 & 22,9 & 29,3 & 12,1 & 27,9 \\
\hline $\begin{array}{l}\text { Организация эффективной системы } \\
\text { контроля и проверки исполнения } \\
\text { принимаемых решений } \\
\text { на предприятии }\end{array}$ & 7,1 & 25,7 & 22,9 & 11,4 & 32,9 \\
\hline $\begin{array}{l}\text { Обеспечение уровня социальной } \\
\text { защиты, превышающего } \\
\text { государственный уровень }\end{array}$ & 5,8 & 30,9 & 21,6 & 12,9 & 28,8 \\
\hline $\begin{array}{l}\text { Работа над усилением мотивации } \\
\text { профсоюзного членства }\end{array}$ & 5,0 & 19,1 & 31,2 & 17,0 & 27,7 \\
\hline $\begin{array}{l}\text { Привлечение сотрудников } \\
\text { к управлению предприятием }\end{array}$ & 4,3 & 18,7 & 28,8 & 18,7 & 29,5 \\
\hline
\end{tabular}

Респондентам было предложено оџенить по пятибаммьной шкаме соблюдение руководством предприятия и профсоюзом обязательных требований трудового законодательства (рисунок).

Исследование показало, что наиболее высоко сотрудники оџенили собмюдение законодательства в сфере предоставления больничных и декретных отпусков (4,88 бамла), закмючения трудового договора с сотрудником (4,77 бамма) и выпматы выходного пособия (4,7 бамма). Меньше всего респондентов устраивает соблюдение трудового законодательства в области соот- 
ветствия оплаты труда работника занимаемой должности (3,68 бамла), ознакомления сотруАника преАприятия с кажАой записью, вносимой в трудовую книжку (3,55 бамма), и соблюдения условий конкурсного отбора на Аомжности (3,08 бамиа).

В рамках Аанного исследования необходимо было выяснить мнение сотруАников РКП о приоритетных направлениях развития профсоюзной деятельности на предприятиях. Соответственно, основное направление Аеятельности профсоюза, по мнению участников проведенного опроса, - это защита прав и интересов работников (68,7\%). Укучшение условий труда и отдыха работников занимает вторую позицию (41,0\%). Примерно на одном уровне оказались такие направления профсоюзной работы, как обеспечение уровня соџиальной защиты, превышающего государственный $(30,6 \%)$, и содействие в создании условий Аля профессионального роста (30,6\%). Менее значимыми дмя работников предприятий РКП явцяется привлечение сотруАников к управлению преАприятием $(13,4 \%)$ и созАание условий Аля Ауховного и нравственного развития чиенов профсоюза $(9,7 \%)$. Это означает, что развитие деятельности в области защиты прав и интересов работников явмяется крайне важным Аця сотрудников преАприятий РКП.

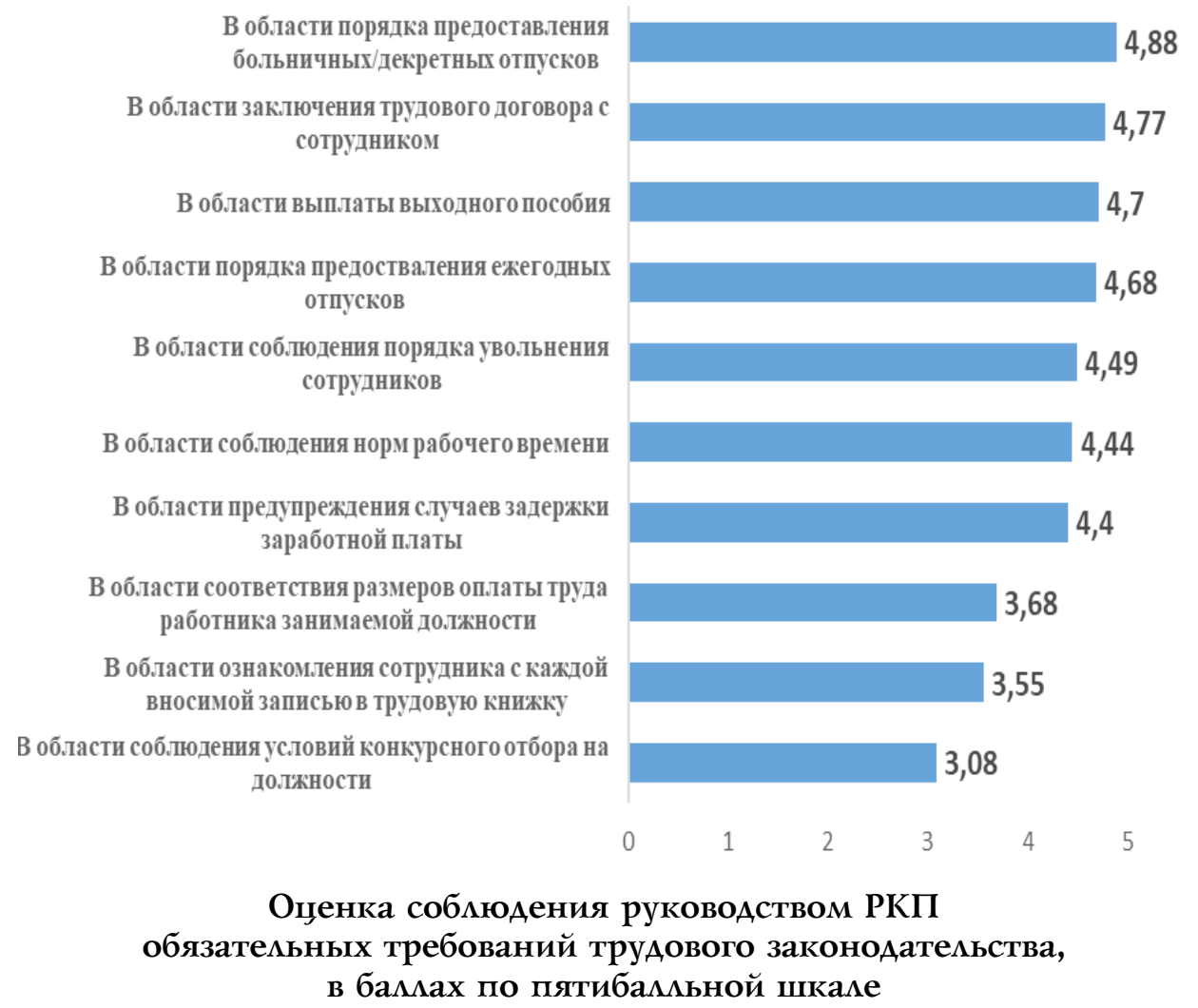

82 Bulletin of the Volga Region Institute of Administration • 2018. Vol. 18. № 6 
Коммективный договор - важнейший правовой акт, приспособленный к конкретным условиям трудового коммектива данного предприятия. Он имеет смешанную юридическую природу, поскольку закрепляет цокальные нормы, превышающие соџиальные гарантии, и основан на согласии работодатемя (администрации) и работников (трудового коммектива) как социамьных партнеров на конкретном предприятии. Аیя работодателя коммективный Аоговор - один из инструментов регулирования соџиально-трудовых отношений, снижения соџиальной напряженности и вовлечения работников в реализаџию стратегии развития корпораџии. Это важный фактор, влияющий на формирование положительного отношения сотрудников к корпоративным ценностям и политике работодателя. Благодаря комлективному Аоговору интересы работника приобретают правовую форму и их можкно отстаивать с помощью государственного регулирования.

На вопрос о заключении работниками с предприятиями РКП комективных договоров большинство респондентов ответили положительно (69,2\%).

Комлективный договор явмяется важным эмементом трудовых взаимоотношений, поэтому авторами рассмотрен вопрос о соблюдении на преАприятиях РКП основных положений Аанного документа.

Согласно приведенным результатам опроса респондентов о соблюдении положений комлективного договора на предприятиях РКП, больше половины работников в возрастных группах до 25 мет и от 36 до 45 мет $(63,2$ и 66,7\%, соответственно) считают, что положения коммективного договора соблюдаются (табл. 2). Необходимо отметить, что сотрудники в возрастной группе от 36 до 45 мет не выбрали ответ: «Я ничего не знаю о комлективном договоре», а это наиболее активная группа сотрудников на преАприятиях РКП. Следовательно, респонденты этого возраста не владеют необходимой информацией или до них не доведена информаџия о заключении комлективных договоров с сотрудниками предприятий.

Таблииа 2

Распределение ответов на вопрос: «Как бы Вы оценияи соблюдение основных положений коллективного договора на вашем предприятии?», \% от числа опрошенных в разных возрастных группах

\begin{tabular}{|c|c|c|c|c|c|c|c|}
\hline \multirow{2}{*}{ Ответ } & \multicolumn{6}{|c|}{ Возраст респондентов, лет } & \multirow{2}{*}{ Итого } \\
\hline & до 25 & $26-35$ & $36-45$ & $46-55$ & $56-65$ & старше 65 & \\
\hline $\begin{array}{l}\text { Все положения } \\
\text { соблюдаются }\end{array}$ & 63,2 & 34,7 & 66,7 & 34,8 & 42,9 & 16,7 & 43,9 \\
\hline $\begin{array}{l}\text { Некоторые положения } \\
\text { не соблюдаются }\end{array}$ & 10,5 & 18,4 & 14,3 & 21,7 & 23,8 & 33,3 & 18,7 \\
\hline $\begin{array}{l}\text { Я ничего не знаю } \\
\text { о коллективном договоре }\end{array}$ & 5,3 & 16,3 & & 8,7 & 9,5 & 16,7 & 10,1 \\
\hline Затрудняюсь ответить & 21,1 & 30,6 & 19,0 & 34,8 & 23,8 & 33,3 & 27,3 \\
\hline Итого & 100,0 & 100,0 & 100,0 & 100,0 & 100,0 & 100 & 100,0 \\
\hline
\end{tabular}


Комективный договор по своей сути формирует социальную политику. ОАной из его составных частей являются дополнительные соџиальные обязательства: гарантии и мьготы, стимулирующие работников, которые взял на себя работодатель.

Стимулирование труда работников - важнейшее направление осуществления соџиальной политики на предприятии. Существуют стимулы как материальные, так и нематериальные. К материальным относятся денежные и неденежные (натуральные) средства мотивации. Заработная плата, надбавки, выплаты стимулирующего характера, премии, компенсаџии, доплаты относятся к материальным стимулам. Заработная плата состоит из трех составцяющих: основная часть, Аополнительные выплаты (премии, надбавки и т.п.), а также выплаты и мьготы соџиального характера (например, материальная помощь, оплата медищинских услуг и Ар.). В период плановой экономики все вопросы, связанные с ценой труда, находились поА контролем государства. Заработная плата устанавливалась в рамках единой тарифной сетки Аля всех работников и быма ориентирована на принцип социальной уравнительности. Предприятия не имели права самостоятельного решения вопросов в области оплаты труда. Контролировалось и строго регмаментировалось все: фонд заработной платы, форма опматы, квалификационные различия, профессиональные качества, средний уровень заработанных среАств. Соџиальную политику предприятий в СССР к началу 1990-х годов можно определить в следующих терминах: «соџиалистический корпоративизм», «этакратизм», «патернализм», «эналитаризм» [6-8]. Иными словами, еАинственным собственником преАприятия, единственным источником финансирования соџиальной сферы и единственным работодателем явмялось государство.

Из всех соџиальных услуг самыми распространенными были оказание меАиџинских услуг и материальная помошь. С начала 1990-х годов произошло снижение объема и доступности предоставления соџиальных услуг на регуцярной основе, они стали носить еАиновременный характер [9]. В это время на преАприятиях большое внимание начинают удемять экономической оптимизаџии предоставцяемого соџиального пакета, его использованию адресно и в качестве стимулирования труда и развития персонала. Государство за годы реформ практически отстранилось от регулирования зарплат на преАприятиях. Премии и стимулирующие надбавки стали носить мотивационный характер, их выплаты не были гарантированы и к 2002 г. на предприятиях закрепились патерналистские отношения. Эти изменения коснулись соџиальных мьгот и услуг. Социальный пакет носит компенсационный характер относительно невысокого уровня заработных плат на предприятиях и активно используется Аля сохранения духа корпоративизма и стимулирования труда работников (основная его задача - удержание высококвалифицированных кадров). При предоставлении на предприятиях соџиальных благ учитывается квалификация сотрудников и стаж работы. Предпочтения отдаются работникам с большим стажем.

Формирование соџиального пакета должно осушествляться предприятиями 
в зависимости от финансовых возможностей. С учетом развития экономики в стране можно ожкиать, что значимость социального пакета на предприятиях РКП будет нарастать с каждым годом. Он станет инструментом мотиваџии персонала и управления чемовеческими ресурсами - как действующими, так и потенциальными.

В рамках проведенного социологического исследования сотрудникам преАприятий РКП был задан вопрос: «Какие из перечисленных элементов социального пакета реацизует ваше предприятие?» Сотрудники предприятий РКП прежде всего выделяют следующие элементы соџиального пакета: «Подарки на праздники, билеты на новогодние елки Аля Аетей сотрудников» (84,1\%), «Аобровольное медицинское страхование» (70,0\%), «Оплачиваемое обучение» (68,6\%), «Предоставление жилья иногородним. Компенсация расходов за аренду жицья» (58,0 \%). Респонденты также отметици эмементы соџиального пакета, которые, по их мнению, не реализуются на предприятиях РКП: «Наличие столовой с беспиатным питанием или доставка обеАов из кафе (ресторана)» $(85,5 \%)$, «Оплата транспортных расходов» $(66,7 \%)$ и «Корпоративные тренинги, мастер-классы, дополнительное образование, например, занятия по иностранному языку» (50,0\%).

Жицищная проблема в России остается одной из самых наболевших и приоритетных. Предприятия РКП иибо предоставцяют жицье сотруАни-

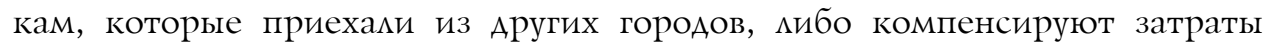
за аренду. На вопрос о возможности приобретения собственного жииья только 8,7\% респондентов ответици, что такая возможность им преАоставмяется при получении ссуды на приобретение жицья ици беспроцентных креАитов.

В результате соџиологического исследования выявлено, что абсолютному большинству респондентов предприятий РКП известно о деятельности профсоюзных организаций, и толыко треть опрошенных не знает о существовании комлективного Аоговора. Наиболее высоко респонденты оџенили эффективность работы профсоюзной организации по таким направлениям деятельности, как создание условий Аля культурного и нравственного развития членов профсоюза, улучшение условий труда и отдыха, защита прав и интересов сотруАников.

С позиџии соблюдения российского трудового законодательства, по мнению респондентов, на преАприятиях РКП выполняются требования в области предоставления больничных и декретных отпусков, оформиения трудового Аоговора, выплаты выходного пособия при увольнении.

Предприятия РКП осознают свою ответственность за выполнение обязательств переА сотруАниками не только в рамках своей основной производственной деятельности, но и в соџиальной сфере, стремясь улучшить качество жизни работников и членов их семей. Сотрудникам предоставляется возможность беспиатного обучения (повышения квалификации), медиџинского обслуживания (в одной из кучших поликлиник города - медсанчасти № 170), иногородним предоставцяется жицье ици компенсируется аренда жкилья, Аетям сотруАников предоставцяются подарки и билеты на новогод- 
ние елки, производится компенсация расходов на отдых детей в магерях и базах отаыха.

Вместе с тем преАприятиям РКП в сфере соблюдения трудового законодательства следует активизировать работу в области соответствия опиаты труда работника занимаемой доцжности и соблюдения условий конкурсного отбора на должности. Профсоюзам необходимо повысить эффективность деятельности в области работы наА усилением мотивации профсоюзного чценства и привлечения сотрудников к управлению предприятием, а также продолжить развивать такие направления деятельности, как защита прав и интересов работников и улучшение условий труаа и отдыха.

\section{Библиографический список}

1. Долгорукова И.В. Современные практики реализации корпоративной социальной политики на российских предприятиях // Вестник МГИМО-Университета. 2014. № 3. С. 206-214.

2. Конституция Российской Федерации. М., 2015.

3. Путин рассказал о важности социальной ответственности бизнеса. URL: https://riamo. ru/article/279024/putin-rasskazal-o-vazhnosti-sotsialnoj

4. Федченко И.В. Корпоративная социальная ответственность: учебное пособие. Красноярск, 2017.

5. Московская A.A. Рынок как фактор возрождения советских форм предоставления социальных льгот и услуг работникам промышленных предприятий // Журнал исследований социальной политики. 2007. Т. 5, № 3. С. 295-318.

6. Чернышова А.Г. Профсоюз как гарант социальной ответственности перед трудящимися предприятий РКП // Инновационные аспекты социально-экономического развития региона: сборник статей по материалам участников VIII ежегодной научной конференции аспирантов МГОТУ. М., 2018. С. 500-507.

7. Кирилина Т.Ю., Чернышова А.Г. Социальная политика на предприятиях ракетно-космической отрасли: состояние и перспективы // Социальная политика и социология. 2017. Т. 16, № 3 (122). С. 95-104.

8. Кирилина Т.Ю., Чернышова А.Г. Специфика социальной политики на предприятиях ракетно-космической отрасли // Россия и современный мир: капитал, солидарность, субъективность: материалы XXII социологических чтений Электронный ресурс]. C. 127-130. URL: https://elibrary.ru/item.asp?id=29272523 2017

9. Сидорина Т.Ю. Социальный капитал и социальная политика российского предприятия // Журнал исследований социальной политики. 2002. Т. 5, № 3. С. 310-334. 